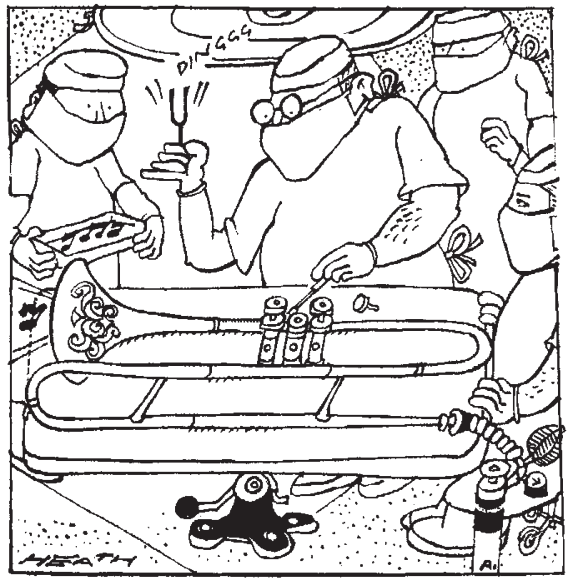

Note paper follows?

A member of the physics department at the University of Surrey, Dr John Bowsher, must be working on one of the most unusual projects to be sponsored by the Science Research Council. $\mathrm{He}$ is to bring the scientific method to bear on the burning problem of why really good trombones sound the way they do. All trombones, it would seem, do not sound the same even though they may look indistinguishable, and it is generally the skill of a craftsman who knows just where to change the shape of a given instrument slightly that saves many new instruments from the ignominy of being $\beta+$ rather than $\alpha$.

With the music company Boosey and Hawkes, who produce 300 trombones a week, relying on the skill of just one craftsman in his 50 s to suggest a little judicious adjustment in such and such a place, Dr Bowsher seems almost to be working against the clock in his analysis of the 'transient qualities' of trombone notes-namely what goes on in the first and last few milliseconds. Fortunately Dr Bowsher and one of his research students are actually trombone players themselves.

\title{
correspondence
}

\section{Czech conditions}

SiR,-The discussion in Nature on the plight of the Czechoslovak scientists and my participation in it has had very unexpected and grave consequence for me personally.

A few days ago I learnt of a decision of the Czech Ministry of Inner Affairs, according to which I have been stripped of my Czech citizenship. The motivations for such an extraordinary decision are given as follows:

(1) The lecture about human rights I gave at the annual meeting of the German section of Amnesty International in June 1974 in Duisburg. (2) My letter to Nature (September 20, 1974), which, I have now learnt, had been broadcast in Czech by Rado Free Europe.

Needless to say, I protest strongly against this decision, which I consider unlawful and contradicting the Universal Declaration of Human Rights as well as other generally valid and accepted declaration and principles.

After being unemployed for more than three years because of my public activity and statements I was allowed to leave Czechoslovakia temporarily in December 1973. When leaving my country I submitted letters to the President of the Czechoslovak Academy of Sciences and to the Ministry of Education, informing them that I was leaving only because I could not find a proper job there, that I would be working abroad as a Czechoslovak scientist and citizen, and that I wished to return home as soon as a job was offered to me.

The decision of the Prague authorities provides another strong argument against the opinion that things are being normalized in Czechoslovakia; it shows what is the real situation and the con- ditions Czechoslovak intellectuals have to live in.

Yours faithfully, Frantisek JanOuch

Stockholm

\section{Citation analysis}

SiR,-Concluding their recent letter (March 13), Pragier and Ronayne, citing Langrish, state "... our results raise serious doubts as to the validity of citation analysis in the determination of the relationship between science and technology."

I suggest that these conclusions have been reached because of a misconception about the scope of citation analysis, and do not, in fact, cast doubts on validity.

Langrish examined citations from articles by British industrial chemists, finding that they were largely of nonuniversity origin, whereas Pragier and Ronayne studied citations from biologically oriented articles in Reports on the progress of applied chemistry, finding them to be mainly of university origin.

From this it may be concluded, as Pragier and Ronayne state, that information was drawn from different sources by these two communities, but this does not mean that such studies are not of value for studying the background of university and industrial science and technology.

What it does mean is that such studies are likely to be most useful when applied to a community whose members are characterised by having an interest in a specific aspect of science.

If the same pairs, triples, quads of references are observed in a number of articles, there is an implied consensus of opinion-the authors are perceiving a relationship between the earlier cited articles. The heavily co-cited articles form the putative 'core' literature of the subject. This technique, originated by $H$. Small, was used to study the literature generated by the scientific community engaged in amorphous (chalcogenide glass) semi-conductor research from 1968 to 1973 . Until 1972 the core articles, with one exception, came from universities.

In 1972 the core was augmented by articles from non-university sources. The cause of this was heavy co-citing of 1972 articles by 1973 authors. These authors often used title words indicating that device applications were described in their articles. It may be concluded that during this period materials, hitherto of research interest, started to

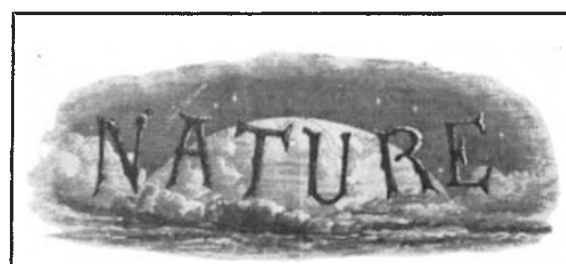

\section{A hundred years ago}

Dingler's Polytech. Journal contains an account of researches made by $\mathrm{Dr}$ Otto Krause, of Annaberg, on tobacco smoke, which he finds contains constantly a considerable quantity of carbonic oxide. The after effects of smoking are said to be principally caused by this poisonous gas, as the smoker never can prevent a part of the smoke from descending to the lungs, and thus the poisoning is unavoidable. The author is of opinion that the after effects are all the more energetic, the more inexperienced the smoker is, and he thus explains the unpleasant results of the first attempts at smoking, which are generally ascribed to niootine alone. from Nature, 11, 456; April 8, 1875 